\title{
Carotid-cavernous fistula, report of a difficult case
}

\section{Fístula carótida cavernosa, reporte de un caso de difícil diagnóstico}

\author{
Sara Chica-Calderón ${ }^{1 *}$, María E. González-Alviar ${ }^{1}$, and Sergio Vargas-Vélez ${ }^{2,3}$ \\ ${ }^{1}$ Ophthalmology Service, Universidad de Antioquia; ${ }^{2}$ Neuroradiology, Professor at the Universidad de Antioquia; ${ }^{3}$ CediMed. Medellín, Colombia
}

\begin{abstract}
We present the case of a 64-year-old female patient with a 7-month history of nonspecific symptoms of diplopia and unilateral proptosis. On physical examination there was a marked limitation of the abduction of the lateral rectus muscle, but magnetic resonance imaging (MRI) showed thickening of the medial rectus. An initial diagnosis of dysthyroid ophthalmopathy was made by a neuroradiologist. Despite treatment, there was no improvement of symptoms so a new evaluation of the MRI was requested, finding signs of a carotid-cavernous fistula. The diagnosis of proptosis is a challenge in ophthalmology. Usually, it is caused by dysthyroid ophthalmopathy; however, other diagnoses should be considered in patients with unusual signs and no improvement with standard treatment.
\end{abstract}

Keywords: Exophthalmos. Carotid-cavernous sinus fistula. Conjunctivitis.

\section{Resumen}

Se presenta el caso de una paciente de 64 años con síntomas inespecíficos, de 7 meses de evolución, de diplopía y proptosis unilateral. Al examen físico muestra una marcada limitación de la abducción del recto lateral, pero en la resonancia magnética se observa principalmente un engrosamiento del recto medio. Se hace diagnóstico de oftalmopatía distiroidea por lectura de neurorradiólogo. Por no mejoría de la paciente con el tratamiento y continuidad de sus síntomas, se pide una relectura de la resonancia, en la que se encuentran signos de una fístula carotidocavernosa. El diagnóstico de proptosis es un reto en oftalmología. En general está causada por una oftalmopatía distiroidea, pero se debe pensar en otros diagnósticos en pacientes con signos inusuales y sin mejoría con el tratamiento estándar.

Palabras clave: Exoftalmos. Fístula carotidocavernosa. Conjuntivitis.

\section{Introduction}

Carotid cavernous fistulas are abnormal communications between the carotid artery and the cavernous sinus, directly or through intradural branches of the internal or external carotid artery, that generate an arteriovenous shunt. They can be of spontaneous origin (congenital, degenerative, infectious) or more commonly traumatic (up to $75 \%$ of cases). Barrow, et al. ${ }^{1}$ classified them, according to the angiographic findings, into two types: direct (type A) and dural or indirect (types B, $C$, and $D)^{2}$. From the pathophysiological point of view,
Available online: 01-09-2021 Rev Mex Oftalmol (Eng). 2021;95(5):214-218 www.rmo.com.mx 2604-1731/@ 2020 Sociedad Mexicana de Oftalmología. Published by Permanyer. This is an open access article under the CC BY-NC-ND license (http://creativecommons.org/licenses/by-nc-nd/4.0/). 
there is a hemodynamic dysfunction within the cavernous sinus with congestive and ischemic effects ${ }^{1,3,4}$.

High-flow or direct fistulas are caused by the rupture of the internal carotid artery within the cavernous sinus. The clinical picture is dramatic and occurs mainly due to trauma or rupture of an aneurysm, and less frequently after Le Fort I osteotomy. Low-flow or indirect ones occur due to rupture, generally spontaneous, of small-caliber branches of the internal or external carotid artery and cavernous sinus. The cause of these fistulas is still controversial. One hypothesis indicates the rupture of the thin walls of the dural arteries that cross the cavernous sinus; another states that they develop in response to spontaneous venous thrombosis in the cavernous sinus ${ }^{3}$.

These fistulas are very difficult to diagnose due to their low specificity and because they are indolent. They occur more frequently in perimenopausal women. They are attributed to several causes, such as congenital anomalies, spontaneous venous hypertension due to thrombosis, arteriosclerosis, collagen diseases, syphilitic arteritis, and iatrogenic vascular damage.

In addition to compressive symptoms, there is increased flow, elevated intracavernous pressure, and retrograde flow that induces orbital venous hypertension, pulsatile exophthalmos, chemosis, retinal venous and episcleral vessel congestion, headache, and orbital pain. The frontal-orbital murmur is synchronous with the pulse when reclining is pathognomonic. The main affected cranial nerves that limit the extraocular muscles are, by frequency, the VI (contiguous to the internal carotid artery, intracavernous), the III, the IV, and the V in their branches 1 and 2 (also intracavernous); these can suffer compression in disorders of the cavernous or adjacent sinus. Ptosis and diplopia are early, the latter being the most common manifestation, due to compression of the oculomotor muscles. The severity depends on the amount of flow and the venous drainage capacity ${ }^{5-8}$.

Imaging usually shows dilation of the superior orbital vein (non-fistula specific), lateral bulging of the cavernous sinus, thickening of the extraocular muscles, and abnormal flow in the cavernous sinus.

In the absence of anterior drainage or dilation of the superior ophthalmic vein, it is essential to perform a magnetic resonance angiography with gadolinium. If there is a fistula, engorgement of the sinus is observed, with a sensitivity of $83 \%$ and a specificity of $100 \%$. However, this technique can not define the involved arteries or cortical venous drainage, which is why conventional angiography is superior ${ }^{4}$.
If symptoms are stable, the patient is just observed. Thirty percent of cases are solved by compression maneuvers ${ }^{3}$. However, close monitoring is advisable because rapid visual or functional deterioration of the cranial nerves may occur due to increased intraocular pressure, given the retrograde venous return through the superior ophthalmic vein.

The first successful treatment was performed by the British surgeon Travers, by ligating the common carotid artery. Since then, therapeutic advances have been substantial. Treatment should be urgent in cases of intracranial hypertension, neurological deficits, visual loss, transient ischemic attack, etc.

Endovascular therapy varies depending on the type of fistula. The artery can be sacrificed above and below the fistula ("entrapment") with coils or other devices. Another option is the transarterial, transvenous, or combined endovascular approach for fistula occlusion with liquid agents, coils, or covered stents (with arterial preservation). Transvenous packing of the cavernous sinus with coils is more challenging in direct fistulas, compared to that performed in a dural arteriovenous malformation; furthermore, fistulas have a high flow volume and require very dense packing to induce thrombosis in the venous portion. Fiber coils offer advantages despite their rigidity and tendency to kickback from the microcatheter. There is a risk of migration of coils or liquid agents from the venous to the arterial side, which can be addressed with the transarterial placement of a temporary balloon that occludes the fistula. Transvenous treatment of arteriovenous fistulas aims to eliminate them completely but avoiding the end result of intracranial venous reflux. Covered stents have been used in carotid-cavernous fistulas by many authors when other alternatives have failed $d^{9,10}$.

\section{Clinical case}

A 64-year-old woman came to the consultation, referring that her "left eye is bulging out and diplopia." The symptoms started 7 months ago with a sudden sensation of mass and pressure in the left eye, burning, pain, diplopia, and bilateral eyelid edema. She denied a history of trauma. She was treated multiple times with steroids, without improvement. When interrogated, she reported a chronic headache. Ocular examination revealed normal bilateral visual acuity, anisocoria, and afferent pupillary defect in the left eye. In the red saturation test, a red desaturation of $40 \%$ is observed on the left side. Left ocular motility had a -4 lateral rectus 

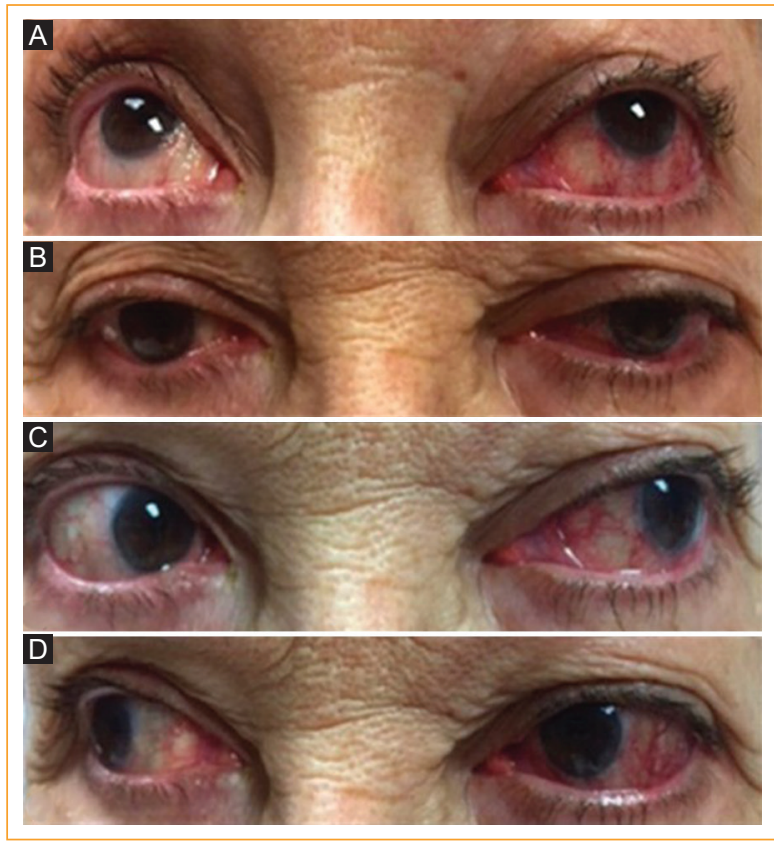

Figure 1. Clinical examination of ocular motility.

A: supraversion. B: infraversion. C: levoversion with marked hypofunction of the lateral rectus. D: dextroversion.

hypofunction (Fig. 1), and there was mild proptosis of the left eye by exophthalmometry. Biomicroscopic examination of the left eye showed marked nasal and temporal vascular engorgement. Intraocular pressure and refraction were normal in both eyes. Funduscopic examination of the left eye showed tortuous vessels in the superotemporal arch (Fig. 2).

An MRI was performed, and the axial T1 sequence contrasted with fat saturation revealed a diffuse thickening of the extraocular muscles, mainly of the medial rectus, respecting the tendon and muscle insertion, in addition to a 22-mm left ocular proptosis (Fig. 3 A). The first neuroradiology reading suggested a dysthyroid ophthalmopathy as the first diagnosis. Due to the clinical and radiological discrepancy, with hypofunction of the lateral rectus on physical examination and thickening mainly of the medial rectus on the MRI, in addition to not improving with steroids, a new reading was requested by another neuroradiologist, who found signs of a carotid-cavernous fistula in the angioresonance (vascular asymmetry in the left cavernous sinus compared to the right, and dilation of the left superior ophthalmic vein; Fig. 3 B).

After these findings, a cerebral angiography was performed to confirm the diagnosis (Fig. 4 A), which showed a low-flow carotid-cavernous fistula that,

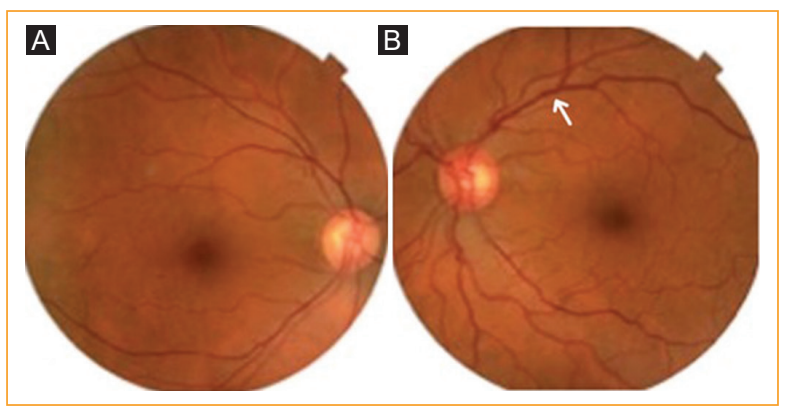

Figure 2. Eye fundus. A: normal right eye. B: left eye with tortuous blood vessels in the temporal arches, mainly superior (arrow).

according to the Barrow classification ${ }^{3}$ (Fig. 3 C), is an indirect type $B$ fistula nourished by the dural branches of the meningohypophyseal trunk of the left internal carotid artery (Fig. 4 A). An endovenous coil embolization was then carried out through the inferior petrosal sinus, until reaching the cavernous sinus (Fig. 4 B). The final angiographic control (Fig. 4 C) showed complete occlusion of the fistula after coil placement.

In the follow-up 4 months after endovascular treatment, the patient was asymptomatic.

\section{Discussion}

This is a patient with chronic unilateral proptosis, marked limitation of the lateral rectus, bilateral eyelid edema, congestion of episcleral vessels and tortuous vessels in the fundus. The MRI found a diffuse thickening of the extraocular muscles, mainly of the medial rectus, and the initial neuroradiological diagnosis was a dysthyroid ophthalmopathy. In a second reading of the angio-MRI, signs suggestive of a carotid-cavernous fistula were observed, later confirmed by an arteriography.

Due to the difficulty in diagnosing low-grade carotid cavernous fistulas, and because they have nonspecific clinical manifestations, it is important to use complementary diagnostic images and to carry out a multidisciplinary approach that helps to make an accurate diagnosis. In the case of clinical and radiological discrepancies, as in this patient, who showed limitation of the lateral rectus (the muscle less frequently involved in thyroid ophthalmopathy), it is very important to consider a second reading of the images by other experts, especially when there is no improvement with treatment. 


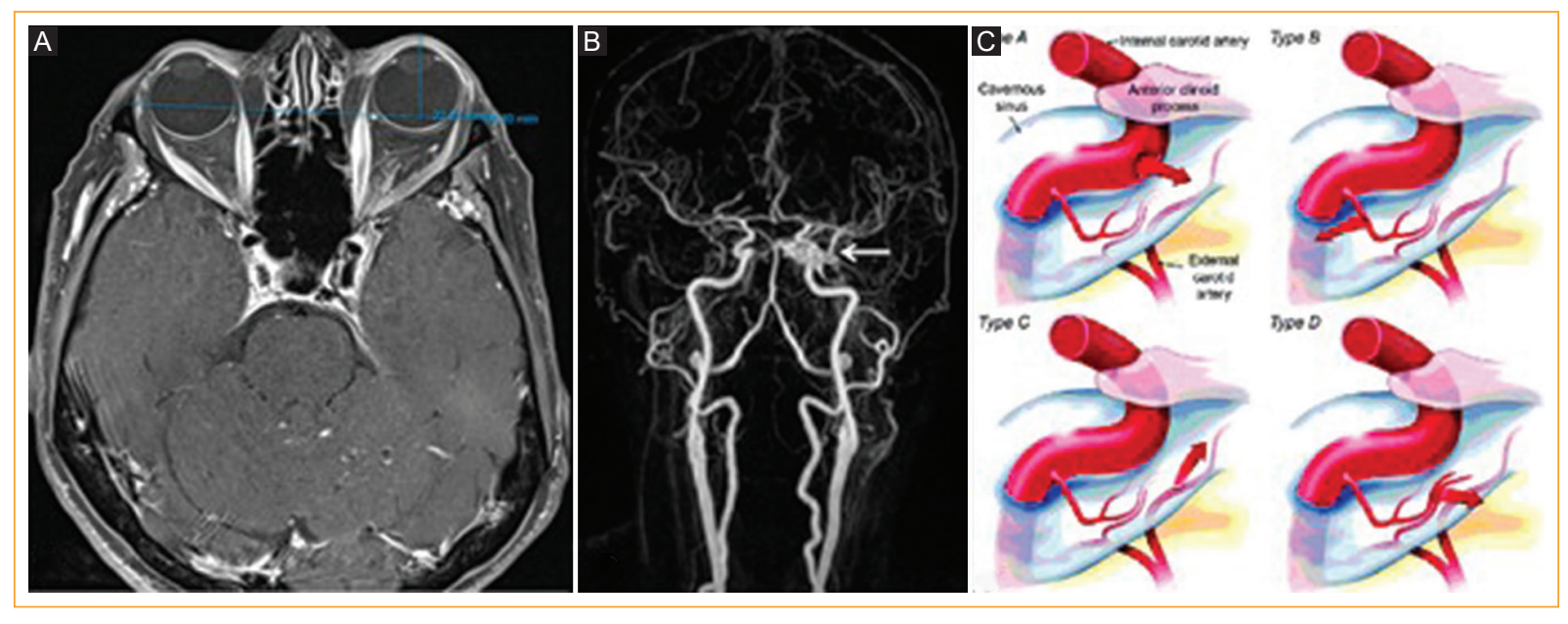

Figure 3. A: axial acquisition of magnetic resonance imaging contrasted in T1 sequence with fat saturation. There is a thickening of the extraocular muscles, mainly of the medial rectus, and a 22-mm left proptosis. B: brain MRI showing asymmetry in the left cavernous sinus (arrow) and dilation of the left superior ophthalmic vein. C: Barrow's classification of carotid-cavernous (taken from Ellis, et al. ${ }^{2}$.

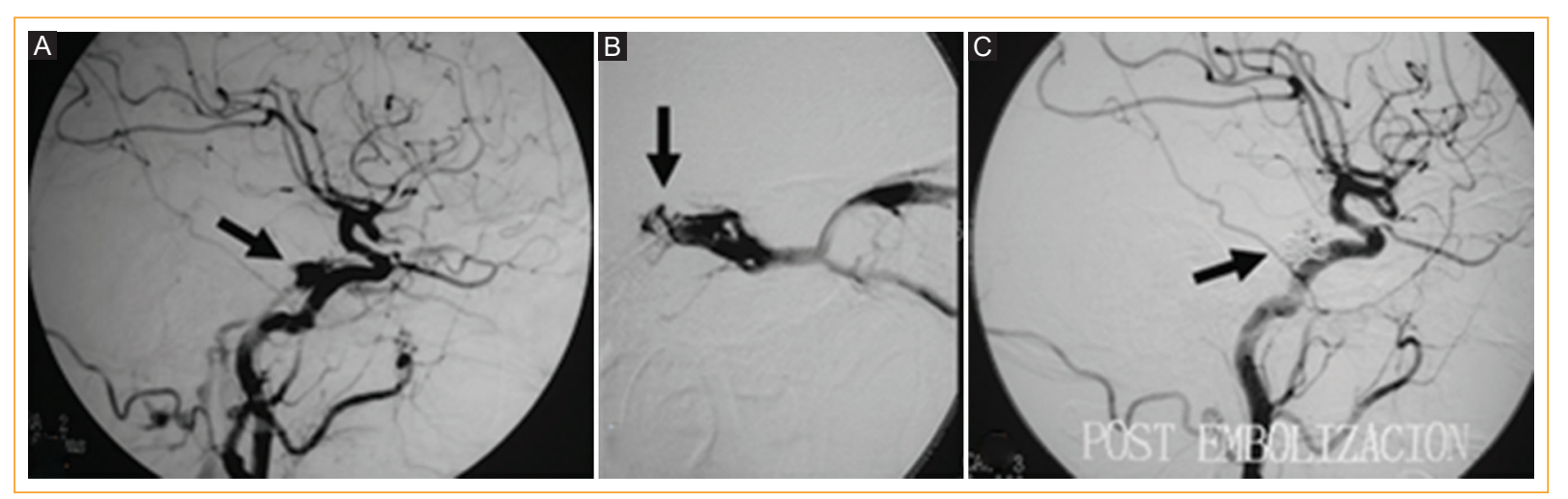

Figure 4. Brain angiography. A: low-flow carotid-cavernous fistula (arrow) nourished by the dural branches of the meningohypophyseal trunk of the left internal carotid artery (Barrow type B). B: endovenous coil embolization through the inferior petrosal sinus until reaching the cavernous sinus. C: post-embolization angiographic control showing complete occlusion of the fistula by the coils.

\section{Conclusion}

Proptosis diagnosis is a challenge in ophthalmology. Despite being the most common cause, proptosis is not always due to dysthyroid ophthalmopathy. When the signs are unusual, differential diagnoses should be considered, ${ }^{6}$ as in the case presented, in which there was a limitation of the lateral rectus when evaluating ocular motility, a rare finding in thyroid orbitopathy $1,5,7,8$.

\section{Conflicts of interest}

The authors declare no conflict of interests.

\section{Ethical disclosures}

Protection of human and animal subjects. The authors declare that the procedures followed were in accordance with the regulations of the relevant clinical research ethics committee and with those of the Code of Ethics of the World Medical Association (Declaration of Helsinki).

Confidentiality of data. The authors declare that they have followed the protocols of their Institution on the publication of patient data.

Right to privacy and informed consent. The authors have obtained the written informed consent of the 
patient mentioned in the article. The corresponding author is in possession of this document.

\section{References}

1. Barrow DL, Spector RH, Braun IF, Landman JA, Tindall SC, Tindall GT. Classification and treatment of spontaneus carotid-cavernous sinus fistulas. J Neurosurg. 1985;62:248-56.

2. Ellis J, Goldstein H, Connolly E, Meyers P. Carotid-cavernous fistulas. Neurosurg Focus. 2012;32:E9.

3. Micieli JA, Bedi H, Krings T. A woman with a red eye from a carotidcavernous sinus fistula. CMAJ. 2017;189:113-5.
4. Abecassis IJ, Morton RP, Kim LJ, Ghodke BV, Levitt MR. Combined direct and indirect traumatic carotid-cavernous fistula (CCF): case report and review of the literature. J Clin Neurosci. 2017;44:240-2.

5. Rootman J. Orbital inflammatory disease, orbital disease, present status and future challenges. 4th ed. Boca Raton: Taylor and Francis; 2005.

6. Buerger DG. Proptosis. En: Gault JA, editor. Ophthalmology secrets in color. 4th ed. Philadelphia: Elsevier; 2016. p. 278-81.

7. Yanoff, M. Ophthalmology. 4th ed. Philadelphia: Elsevier; 2014.

8. Mombaerts I, Bilyk JR, Rose GE, McNab AA, Fay A, Dolman PJ, et al. Consensus on diagnostic criteria of idiopathic orbital inflammation using a modified Delphi approach. JAMA Ophthalmol. 2017;135:769-76.

9. Morris P. Practical neuroangiography. 3rd ed. Philadelphia: Wolters Kluwer Health; 2013.

10. Gonzales L. Neurointerventional techniques. New York: Thieme; 2014. 